\title{
A man with two syndromes
}

\author{
Hadi Mirfazaelian • Farnaz Hourfar • \\ Shahrzad Negahban • Mansour Ansari · \\ Yahya Daneshbod
}

Received: 30 January 2014/ Accepted: 13 February 2014/Published online: 27 February 2014

(C) SIMI 2014

A 40-year-old man was referred to the emergency department because of a low platelet count on a routine complete blood count (CBC). He had an hemangioma on his forearm together with a "congenital deformity" with no other medical problem including hematologic disorder in the past. On physical examination he had an evident hypertrophy of the right side of the trunk and the right upper limb. There was a biopsy mark on his right forearm (Panel A). He had no other vascular or hypertrophic changes in the remainder of his body parts. The physical examination was otherwise normal including the neurologic assessment. The family history was negative. On laboratory study, the platelets were $77,000 / \mu \mathrm{L}$ (Normal $150,000-450,000 / \mu \mathrm{L}$ ) hemoglobin $12.0 \mathrm{~g} / \mathrm{dL}$ (Normal $13.5-17.5 \mathrm{~g} / \mathrm{dL}$ ), and white blood cells (WBC) $8.1 \times 103 / \mu \mathrm{L}$ (Normal 3,500-10,500/ $\mu \mathrm{L}$ ). Coagulation profile showed prothrombin time (PT) $11 \mathrm{~s}$ (Normal 9-12 s), activated partial thromboplastin time (aPTT) $30 \mathrm{~s}$ (Normal 29.0-36 s), D-dimer $370 \mu \mathrm{g} / \mathrm{L}$ (Normal 0-450 $\mu \mathrm{gm} / \mathrm{L}$ ), and fibrinogen $1.9 \mathrm{~g} / \mathrm{L}$ (Normal $1.5-4 \mathrm{~g} / \mathrm{L}$ ). The other laboratory findings were within normal limits.

H. Mirfazaelian ( $\square)$

Department of Emergency Medicine, Tehran University of

Medical Sciences, Tehran, Iran

e-mail: H-mirfazaelian@razi.tums.ac.ir

F. Hourfar

Department of Internal Medicine, Tehran University of Medical

Sciences, Tehran, Iran

S. Negahban · Y. Daneshbod

Department of Pathology, Dr. Daneshbod Laboratory, Shiraz, Iran

M. Ansari

Department of Radiation Oncology, Namazi Hospital,

Shiraz University of Medical Sciences, Shiraz, Iran
The patient presentation is consistent with the diagnosis of the Kasabach-Merritt syndrome in Klippel-Trenaunay syndrome (KTS). KTS is defined as a triad of capillary malformations, congenital varicose veins, and bony and soft tissue hypertrophies. Although most patients demonstrate all three signs of the clinical syndrome, in a case series, $37 \%$ had two of them. Hemangioma, which can be evaluated by Doppler ultrasonography, is seen in $98 \%$ of patients, followed by venous malformations and limb hypertrophy. The hemangioma is typically of the nevus flammeus type, but cavernous hemangiomas or lymphangiomas may also occur [1]. Hypertrophy may be appreciated at birth. It usually progresses during the first years of life. KTS generally affects a single extremity, although cases of multiple affected limbs have been reported. The

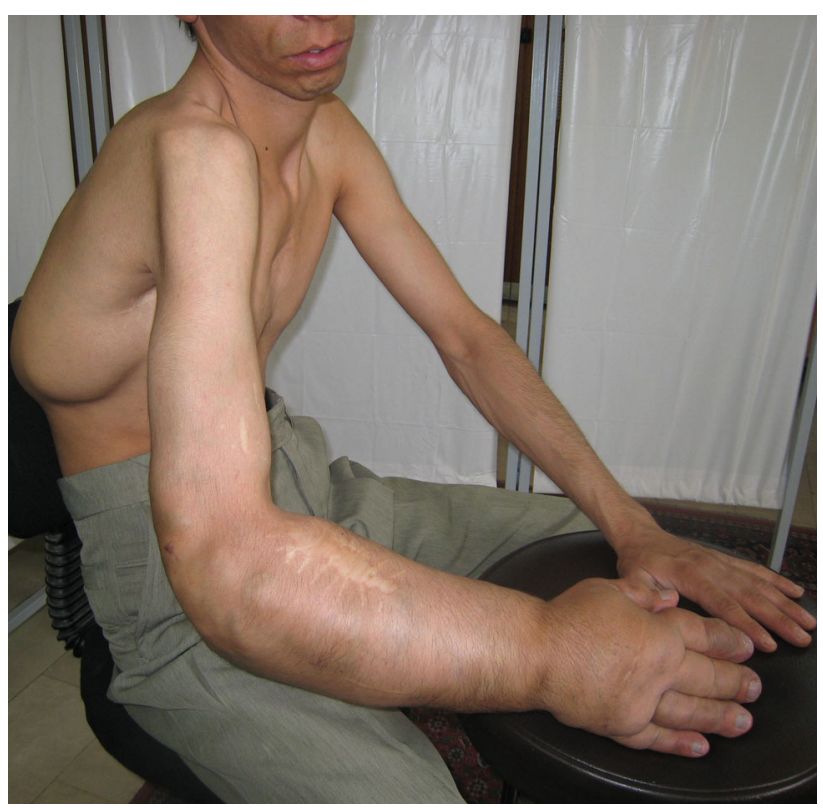


leg is the most common site followed by the arms, the trunk, and rarely the head and the neck [2].

Kasabach-Merritt syndrome is thrombocytopenia and consumptive coagulopathy associated with hemangiomas [3]. The mechanism of thrombocytopenia is unknown, but it is proposed that abnormal endothelial cells within the hemangioma destroy platelets with activation of the coagulation cascade [4]. The management involves hastening hemangioma regression, interfering with platelet trapping within the lesion, and supporting the patient with transfusions. Embolization, radiotherapy, corticosteroids, and alpha interferon have been successfully used in many patients [5]. Since the throbmbocytopenia was mild, the patient was discharged with low-dose steroid, and followed up uneventfully.
Conflict of interest None.

\section{References}

1. Fishman SJ, Mulliken JB (1993) Hemangiomas and vascular malformations of infancy and childhood. Pediatr Clin North Am 40(6):1177

2. Akcali C et al (2008) A case of Klippel-Trenaunay syndrome involving only upper limbs. Giornale italiano di dermatologia e venereologia: organo ufficiale, Societa italiana di dermatologia e sifilografia 143(4):267-269

3. Kasabach HH, Merritt KK (1940) Capillary hemangioma with extensive purpurareport of a case. Am J Dis Child 59(5):1063-1070

4. Hillman RS, Phillips LL (1967) Clotting-fibrinolysis in a cavernous hemangioma. Arch Pediatr Adolesc Med 113(6):649

5. Akyüz C et al (2003) Successful treatment with interferon alfa in infiltrating angiolipoma: a case presenting with Kasabach-Merritt syndrome. Arch Dis Child 88(1):67-68 